\title{
Inventory Investment and the Real Interest Rate
}

\author{
Sadaquat Junayed and Hashmat Khan \\ Carleton University
}

\begin{abstract}
The relationship between inventory investment and the real interest rate has been difficult to assess empirically. Recent work has proposed a linear-quadratic inventory model with time-varying discount factor to identify the effects of the real interest rate on inventory investment. The authors show that this framework does not separately identify the effects of real interest rate on inventory investment from variables that determine the expected marginal cost of production. In other words, the model does not deliver a testable restriction on the impact of interest rates on inventory investment. The authors highlight the consequences for both short- and long-run empirical analyses. They conclude that understanding the relationship between inventory investment and the real interest rate continues to be a theoretical and empirical challenge for macroeconomists.
\end{abstract}

JEL: E22

Keywords: Inventory investment; real interest rate

\section{Correspondence}

Hashmat Khan Department of Economics, Carleton University, D891 Loeb, 1125 Colonel By Drive, Ottawa, K1S 5B6, Canada, E-mail: Hashmat_Khan@carleton.ca

Sadaquat Junayed, Department of Economics, Carleton University, 1125 Colonel By Drive, Ottawa, K1S 5B6, Canada; E-mail: Sadaquat_Junayed@carleton.ca

The authors thank two anonymous referees for helpful comments. 


\section{Introduction}

Business reports and financial media often link higher interest rates to lower inventory investment by firms. In contrast, the academic literature has found little influence, if any, of a relationship between real interest rates and inventories. This discrepancy led Blinder and Maccini (1991) to note that

It is not clear whether the trouble is with the theory or with the empirical tests... Whatever the reason, the question of why inventory investment seems insensitive to changes in real interest rates remains open, important, and troublesome.

Moreover, monetary policy makers pay close attention to inventory movements in their deliberations on interest rate decisions. ${ }^{1}$ To the extent that the real interest rate plays a role in the monetary policy transmission mechanism, the relationship between the real interest rate and inventory investment is of interest and importance to policy makers.

One channel by which the real interest rate may influence inventory investment is via the discount factor. But in the linear-quadratic framework with Euler equation estimation, authors have typically assumed a constant discount factor to facilitate estimation of structural parameters associated with other important issues. See, for example, West (1986), Eichenbaum (1989), Ramey (1991), and Ramey and West (1999). In the production function literature, authors have allowed for a variation in the real discount factor but have either found no evidence or some evidence of a relationship between the real interest rate and inventories. See, for example, Miron and Zeldes (1988), Ramey (1989), Kahn (1992), and Bils and Kahn (2000).

In a recent paper, Maccini et al. (2004) propose a modified linear-quadratic inventory model with time-varying real discount factor. They show that the linearized Euler equation of this model the real interest rate enters with its own coefficient, which is then estimated. A key motivation behind this approach is that one could potentially estimate the structural parameters determining the real interest rate-inventory relationship, thereby overcoming the criticisms of the earlier reduced-form literature (see, for example, Akhtar (1983)).

We show that in the Maccini et al. (2004) model, the real interest rate does not enter the Euler equation with its own coefficient under the model's restriction. This restriction implies that the coefficient on the real interest rate in the model depends on structural parameters. As it turns out, the effects of expected real interest rate movements on inventories cannot be separately identified from the variables determining expected marginal cost. The framework, therefore, does not deliver a testable restriction on the impact of interest rates on inventory investment. We provide the intuition for this result. The implication is that empirical work based on the Euler equation derived from the time-varying real discount factor model is insufficient for understanding the structural relationship between inventory investment and the real interest rate (in either the short- or long-run). Therefore, it does not offer any particular advantage relative to the earlier literature which used the traditional reduced-form approach.

\section{The Model}

To illustrate our main point, we consider the linear-quadratic inventory model with time varying real discount factor proposed by Maccini et al. (2004). A representative firm

\footnotetext{
${ }^{1}$ See, for example, the recent minutes of the Federal Open Market Committee, August 11-12, 2009 at http://www.federalreserve.gov/monetarypolicy/files/fomcminutes20090812.pdf.
} 
minimizes the present value of its expected per-period real costs, $\left\{C_{t}, C_{t+1}, \ldots, C_{t+j} \ldots\right\}$ at time $t$. In any given period, $t$, these costs are assumed to be quadratic and given as

$$
C_{t}=\xi W_{t} Y_{t}+\frac{\theta}{2} Y_{t}^{2}+\frac{\gamma}{2}\left(\Delta Y_{t}\right)^{2}+\frac{\delta}{2}\left(N_{t-1}-\alpha X_{t}\right)^{2}
$$

The first and the second terms in (1) represent production costs, the third term represents adjustment costs associated with changing output levels (eg. hiring and firing costs), and the last term represents the conventional accelerator term reflecting a balancing of inventory holding and stockout costs. Real costs depend on two endogenous variables, namely, real output $Y_{t}$, and beginning-of-period $t$ real finished goods inventories, $N_{t-1}$. They also depend on two exogenous variables, namely, $W_{t}$, a real observable cost shock due to variations in input prices, and $X_{t}$, real sales. There are five structural parameters denoted as $\theta, \gamma, \delta, \xi$, and $\alpha$ which are all positive. $\Delta$ is the first-difference operator. From $(1)$, the marginal cost is given as

$$
M C_{t}=\theta Y_{t}+\xi W_{t}
$$

For a given period, the change in inventory, or the inventory accumulation constraint, is simply the difference between production and sales. The real discount factor, $\beta_{t}$, is timevarying and defined as $\beta_{t}=1 /\left(1+r_{t}\right)$, where $r_{t}$ is the real interest rate. Formally, the firm's optimization problem at time $t$ is to choose $N_{t}$ by minimizing the present discounted value of real expected costs

$$
\operatorname{Min} E_{t} \sum_{j=0}^{\infty}\left[\prod_{i=1}^{j} \beta_{t+i}\right] C_{t+j} \text { subject to } \Delta N_{t+j}=Y_{t+j}-X_{t+j}
$$

The first order condition of (3) gives the inventory Euler equation

$$
\begin{array}{r}
E_{t}\left\{\theta\left(Y_{t}-\beta_{t+1} Y_{t+1}\right)+\gamma\left(\Delta Y_{t}-2 \beta_{t+1} \Delta Y_{t+1}+\beta_{t+1} \beta_{t+2} \Delta Y_{t+2}\right)\right)+\xi\left(W_{t}-\beta_{t+1} W_{t+1}\right) \\
\left.+\delta \beta_{t+1}\left(N_{t}-\alpha X_{t+1}\right)\right\}=0
\end{array}
$$

Linearizing (4) around the steady state values $\left\{\bar{\beta}=\frac{1}{1+\bar{r}}, \bar{Y}, \bar{W},\right\}$ we get

$$
\begin{array}{r}
E_{t}\left\{\theta\left(Y_{t}-\bar{\beta} Y_{t+1}\right)+\gamma\left(\Delta Y_{t}-2 \bar{\beta} \Delta Y_{t+1}+\bar{\beta}^{2} \Delta Y_{t+2}\right)\right. \\
\left.+\xi\left(W_{t}-\bar{\beta} W_{t+1}\right)+\delta \bar{\beta}\left(N_{t}-\alpha X_{t+1}\right)+\eta r_{t+1}+c\right\}=0
\end{array}
$$

where $\eta=\bar{\beta}(\theta \bar{Y}+\xi \bar{W})>0, c=-\bar{r} \bar{\beta}(\theta \bar{Y}+\xi \bar{W})<0$. The Euler equation (5) forms the basis of Maccini et al. (2004)'s short- and long-run empirical analysis.

\section{Effect of Interest Rate}

Imposing the model's implied restriction $\eta=\bar{\beta}(\theta \bar{Y}+\xi \bar{W})$ in (5) results in the linearized Euler equation under time-varying discount factor:

$$
\begin{array}{r}
E_{t}\left\{\theta\left(Y_{t}-\bar{\beta} Y_{t+1}+\bar{\beta} \bar{Y} r_{t+1}\right)+\gamma\left(\Delta Y_{t}-2 \bar{\beta} \Delta Y_{t+1}+\bar{\beta}^{2} \Delta Y_{t+2}\right)+\xi\left(W_{t}-\bar{\beta} W_{t+1}+\bar{W} r_{t+1}\right)+\right. \\
\left.\delta \bar{\beta}\left(N_{t}-\alpha X_{t+1}\right)+c\right\}=0
\end{array}
$$

From (6), it is evident that the real interest rate does not have its own coefficient in the Euler equation as in (5). The effects of real interest rate on inventory investment cannot be disentangled from those variables determining the marginal cost of production. The 
model, therefore, does not deliver a testable restriction on the impact of interest rates on inventory investment. The influence of expected real interest rate on inventories is captured by the two structural cost parameters $\theta$ and $\xi$ which determine the slope and the level of marginal cost, respectively. The intuition behind this is that the real interest rate acts as a shock to future marginal costs of the firm. To see this, we can isolate the terms involving future output, cost shock, and the real interest rate in (6), and denoting the effective expected marginal cost as $\widetilde{M C}_{t+1}$, write

$$
\begin{aligned}
\widetilde{M C}_{t+1} & \equiv \theta \bar{\beta}\left(Y_{t+1}-\bar{Y} r_{t+1}\right)+\xi \bar{\beta}\left(W_{t+1}-\bar{W} r_{t+1}\right) \\
& \equiv \bar{\beta}\left(\left(\theta Y_{t+1}+\xi W_{t+1}\right)-(\theta \bar{Y}+\xi \bar{W}) r_{t+1}\right) \\
& \equiv \bar{\beta}\left(M C_{t+1}-\overline{M C} r_{t+1}\right)
\end{aligned}
$$

using (2) (one period ahead) where $\overline{M C} \equiv(\theta \bar{Y}+\xi \bar{W})$. A higher expected real interest rate, for example, lowers the effective expected marginal cost. This makes producing an additional unit of output less costly tomorrow. As a result, firms choose to lower their current buffer stock and hence decrease inventory accumulation. This implies a lower level of inventory, $N_{t}$, at the beginning of period $t+1$. The extent to which the real interest shock matters to the firm's optimal inventory decision (or, the strength of the intertemporal substitution mechanism) is captured by the marginal cost parameters $\theta$ and $\xi$. Note that the costs of adjusting output levels captured by $\gamma$ do not interact with the real interest rate.

\section{Implications for Empirical Analyses}

In the empirical implementation, variation in the real interest rate would influence estimation of the structural parameters $\theta$ and $\xi$. It is, however, not possible to disentangle the effect of the real interest rate on inventories from other variables, as discussed in section 3.

The empirical analysis in Maccini et al. (2004), for example, is based on (5). In the short-run analysis they use generalized method-of-moments (GMM) and decision rule estimation methods to estimate (5), and their long-run analysis involves embedding (5) within a regime switching framework for the real interest rate and deriving a cointegrating vector among model variables. The main finding in Maccini et al. (2004) is that while the short-run negative relationship between inventory investment and the real interest rate is statistically insignificant, co-integration techniques suggest a significant long-run relationship.

In the short-run analysis, Maccini et al. (2004) estimate parameters $\theta, \xi, \gamma, \alpha$, and $\eta$. But as discussed in section 3, $\eta$ itself depends on $\theta$ and $\xi$ and, therefore, the model does not deliver a testable restriction on the impact of interest rates on inventory investment. The conclusions regarding the short-run relationship between inventory investment based on the estimate $\eta$ can only be interpreted as a reduced-form effect. In this context, the linear-quadratic framework with time-varying discount rate shares the same weakness as the earlier literature which also examined only the reduced-form effects (see Akhtar (1983)).

In the long-run analysis, Maccini et al. (2004) provide simulations of the cost function where the parameters are drawn from the estimates of the cointegrating vector. These simulations compare the cost of not responding to transitory shock versus the cost of not responding to a regime change in the real interest rate. Maccini et al. (2004) consider different configurations of structural parameters, particularly $\theta$ and $\xi$, and keep $\eta$ fixed. 
But since $\eta$ depends on $\theta$ and $\xi$, varying these latter parameters influences the cointegrating vector implied by the model, and may have important implications for the quantitative conclusions drawn concerning the long-run relationship between inventories and the real interest rate. An assessment of this issue is, however, beyond the scope of this note.

\section{Conclusion}

We show that in time-varying discount factor models of inventory investment, the real interest rate does not enter with its own coefficient in the Euler equation under the restriction implied by the model. One cannot, therefore, separately identify the effects of the real interest rate from other variables determining the marginal cost. Put differently, the model does not deliver a testable restriction on the impact of interest rates on inventory investment. We have highlighted the consequences for both short-run and long-run empirical analyses, which suggest that understanding the relationship between real interest rate and inventory investment continues to be a challenge for macroeconomists from both theoretical and empirical perspectives. 


\section{References}

Akhtar, M. A. (1983). Effects of interest rates and inflation on aggregate inventory investment in the United States. American Economic Review, 73(3):319-328.

Bils, M. and Kahn, J. A. (2000). What inventory behaviour tells us about business cycles. American Economic Review, 90(3):458-481.

Blinder, A. S. and Maccini, L. J. (1991). Taking stock: A critical assessment of recent research on inventories. Journal of Economic Perspectives, 5(1):73-96.

Eichenbaum, M. S. (1989). Some empirical evidence on the production level and production cost smoothing models of inventory investment. American Economic Review, 79(4):853864.

Kahn, J. A. (1992). Why is production more volatile than sales? theory and evidence on the stockout-avoidance motive for inventory holding. Quarterly Journal of Economics, 107(2):481-510.

Maccini, L. J., Moore, B. J., and Schaller, H. (2004). The interest rate, learning, and inventory investment. American Economic Review, 94(5):1303-1327.

Miron, J. A. and Zeldes, S. P. (1988). Seasonality, cost shocks, and the production smoothing model of inventories. Econometrica, 56(4):877-908.

Ramey, V. and West, K. D. (1999). Inventories. In Taylor, J. and Woodford, M., editors, Handbook of Macroeconomics, Vol. IB, pages 863-923.

Ramey, V. A. (1989). Inventories as factors of production and economic fluctuation. American Economic Review, 79(3):338-354.

Ramey, V. A. (1991). Nonconvex costs and the behaviour of inventories. Journal of Political Economy, 99(2):306-334.

West, K. D. (1986). A variance bound test of the linear-quadratic inventory model. Journal of Political Economy, 94(2):374-401. 


\section{conomics}

The Open-Access, Open-Assessment E-Journal

\section{Please note:}

You are most sincerely encouraged to participate in the open assessment of this article. You can do so by either rating the article on a scale from 1 (bad) to 5 (excellent) or by posting your comments.

Please go to:

www.economics-ejournal.org/economics/journalarticles/2009-34

The Editor 